\title{
Alteration of stress field brought about by the occurrence of the 2011 off the Pacific coast of Tohoku Earthquake $\left(M_{\mathrm{w}}\right.$ 9.0)
}

\author{
S. Hiratsuka and T. Sato \\ Department of Earth and Environmental Sciences, Hirosaki University, Hirosaki, Aomori, Japan \\ (Received April 5, 2011; Revised May 15, 2011; Accepted May 18, 2011; Online published September 27, 2011)
}

\begin{abstract}
A giant earthquake of $M_{\mathrm{w}} 9.0$ took place off the Pacific coast of Tohoku on March 11, 2011. It caused a large tsunami of 10-20 m and devastated the area along the Pacific coast in northeast Japan. The earthquake altered the stress field in the surrounding region immensely. We have calculated the change in Coulomb Failure Function $(\triangle \mathrm{CFF})$ due to this earthquake to evaluate the effect on aftershocks and future earthquake probabilities. The results suggest that the increased activity of normal-fault earthquakes after the main shock is explained by a large positive $\triangle \mathrm{CFF}$ of 1-5 MPa prevailing over a vast area in and around the main-shock fault zone. The areas adjacent to the northern and southern borders of the fault zone where other large interplate earthquakes might occur are occupied by a positive $\triangle \mathrm{CFF}$ of approximately $0.1 \mathrm{MPa}$. Based on the $\Delta \mathrm{CFF}$ result, the future probability of reverse fault earthquakes in the shallow crust is estimated to be decreased in the land area of Tohoku.
\end{abstract}

Key words: 2011 Tohoku Earthquake, Japan Trench, great earthquake, $\Delta \mathrm{CFF}$, Coulomb Failure Function.

\section{Introduction}

A giant earthquake of $M_{\mathrm{w}} 9.0$ occurred at 02:46 p.m. (JST) on 11 March 2011 off the Pacific coast of Tohoku, northeast Japan. A large tsunami following the earthquake devastated the cities and towns facing the rupture zone on the Pacific coast. An interplate earthquake of $M_{\mathrm{w}} 7.5-8.0$ had been anticipated off the Pacific coast of the Miyagi prefecture in the near future, but an earthquake as large as $M_{\mathrm{w}} 9.0$ had not been regarded as impending. This earthquake is so huge that the stress field in and around the fault zone has been disturbed immensely. In this paper, we look at the change in stress field brought about by this earthquake through the change in the Coulomb Failure Function $(\triangle \mathrm{CFF})$, and discuss its effect on aftershocks and future earthquake probabilities in the surrounding region.

\section{Fault Model}

Figure 1 shows the fault model of this earthquake used for calculating the stress change. This model is based on the configuration of the upper plate interface of the subducted Pacific plate determined by Takeuchi et al. (2008) and the coseismic slip distribution estimated by the Geospatial Information Authority of Japan (GSI) (GSI, 2011a). The top of the fault is situated at a depth of $6.5 \mathrm{~km}$ along the axis of the Japan Trench. The attitude of each fault segment is fitted to the local strike and dip of the plate interface. Along the dip direction, the segments are divided by $10 \mathrm{~km}$ depth intervals down to $50 \mathrm{~km}$. The slip amplitudes are greater than $20 \mathrm{~m}$ over the segments off the Pacific coast of the Miyagi prefecture. Given a rigidity of $40 \mathrm{GPa}$, this

Copyright (c) The Society of Geomagnetism and Earth, Planetary and Space Sciences (SGEPSS); The Seismological Society of Japan; The Volcanological Society of Japan; The Geodetic Society of Japan; The Japanese Society for Planetary Sciences; TERRAPUB.

doi:10.5047/eps.2011.05.013 fault model constitutes a $M_{\mathrm{w}} 8.9$ earthquake. Horizontal displacements calculated for the fault model agree well with the ones observed at the GPS sites of GEONET operated by GSI (GSI, 2011b). This agreement provides a rationale for using the fault model to evaluate the stress change due to the earthquake. The slip direction for each fault segment is assumed to be parallel to the direction of motion of the Pacific plate relative to the North American plate (Altamimi et al., 2007). The static displacements and strains due to slip on fault was calculated using the source code developed by Okada (1992), assuming a half-space medium with a Poisson ratio equal to 0.25 .

\section{Distribution of $\triangle \mathrm{CFF}$ for Selected Target Earthquakes}

In order to investigate the effect of stress change on seismic activity, we look at the change in the Coulomb Failure Function ( $\triangle \mathrm{CFF}$ ) (e.g., Toda et al., 1998). Here, we restrict the target area to northeastern Japan. Based on the general feature of focal mechanisms in northeastern Japan (e.g., Yoshii, 1979) and the focal mechanisms of aftershocks determined by the F-net of the National Research Institute for Earth Science and Disaster Prevention (NIED) (Fig. 2), we select several types of target earthquakes. We apply a friction coefficient of 0.4 to minimize its uncertainty $(0.0-0.75)$ to $\pm 25 \%$ (Toda et al., 1998).

As shown in Fig. 2, many shallow aftershocks with normal-fault mechanisms occurred in and around the mainshock fault zone. Prominent areas for such activity are located near the border of the Fukushima and Ibaraki prefectures and near the trench close to the fault segments of maximum slip. Since normal-fault earthquakes are not common during the interseismic period, it is highly possible that those events were triggered by the giant earthquake. Therefore, we first show the $\triangle \mathrm{CFF}$ for the target events with a 


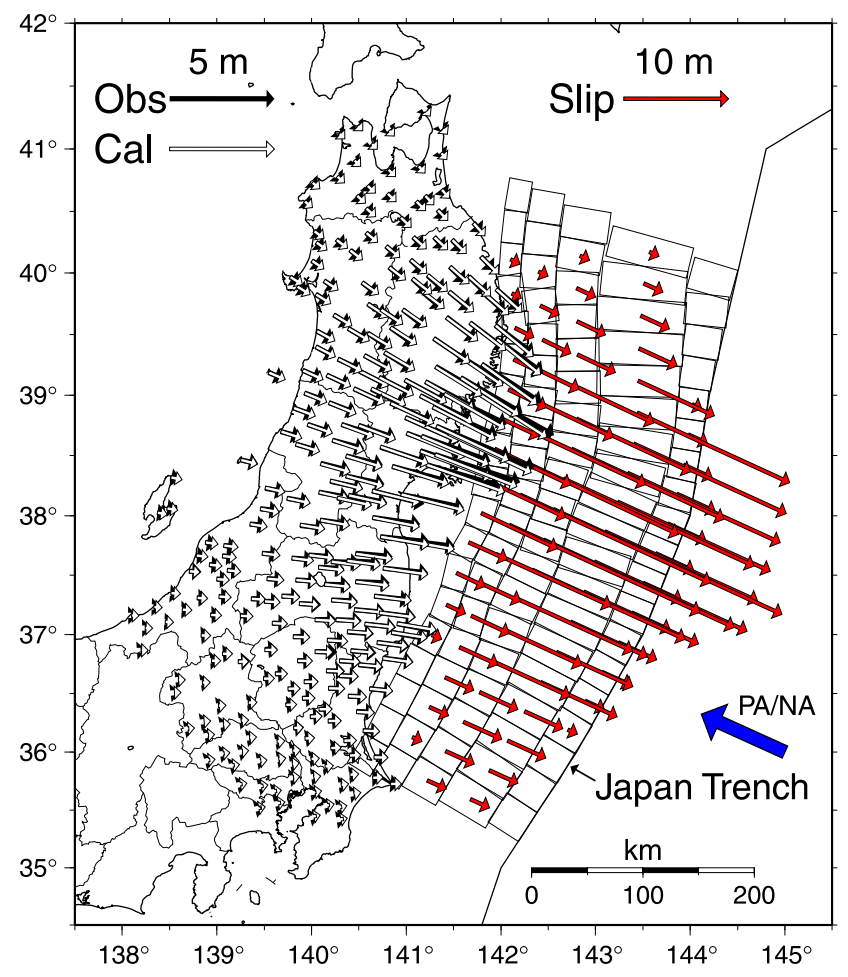

Fig. 1. The fault model used for calculating $\triangle \mathrm{CFF}$. A comparison is made of the observed and calculated horizontal displacements. The observed data are those of GPS sites of GEONET (GSI, 2011b). Slip directions on the fault are assumed to be parallel to the direction of motion of the Pacific plate relative to the North American plate, which is shown by the blue arrow (PA/NA).

normal-fault mechanism in the shallow crust (Fig. 3(left)). Focal depths are assumed to be $10 \mathrm{~km}$. For simplicity, we assume that the fault strikes of target events are parallel to the depth contour of the upper plate interface of the subducted Pacific plate at their epicenters. As regards the fault dips, we consider two cases, one dipping eastwards at $30^{\circ}$ and the other dipping westwards at $60^{\circ}$. The fault rakes are obtained by taking the difference between the fault strikes and slip directions that are assumed to be parallel to the relative direction of motion between the Pacific and North American plates. To save space, we note here that the fault strikes and rakes for other target events to be described later are all defined based on the same assumption. The spatial distribution patterns of $\triangle \mathrm{CFF}$ for the two fault dips are generally similar to each other. Due to lack of space, we show the average of $\triangle \mathrm{CFF}$ obtained for the two fault dips in Fig. 3(left). The area west of the $20 \mathrm{~km}$ depth contour of the plate interface is dominated by a positive $\triangle \mathrm{CFF}$. Their amplitudes range from 2 to $5 \mathrm{MPa}$ over the fault segments with largest slips. It is still as large as $0.2-0.6 \mathrm{MPa}$ at places along the Japan Sea coast of the Akita and Yamagata prefectures. To the east of the $20 \mathrm{~km}$ depth contour of the plate interface, $\triangle \mathrm{CFF}$ first takes a negative value between the 10 and $20 \mathrm{~km}$ depth contours, and then takes a positive value beyond the $10 \mathrm{~km}$ depth contour toward the trench. This change arises because of the shift of the target point from being above to below the plate interface across the $10 \mathrm{~km}$ depth contour of the plate interface. The border of the Fukushima and Ibaraki prefectures, where many

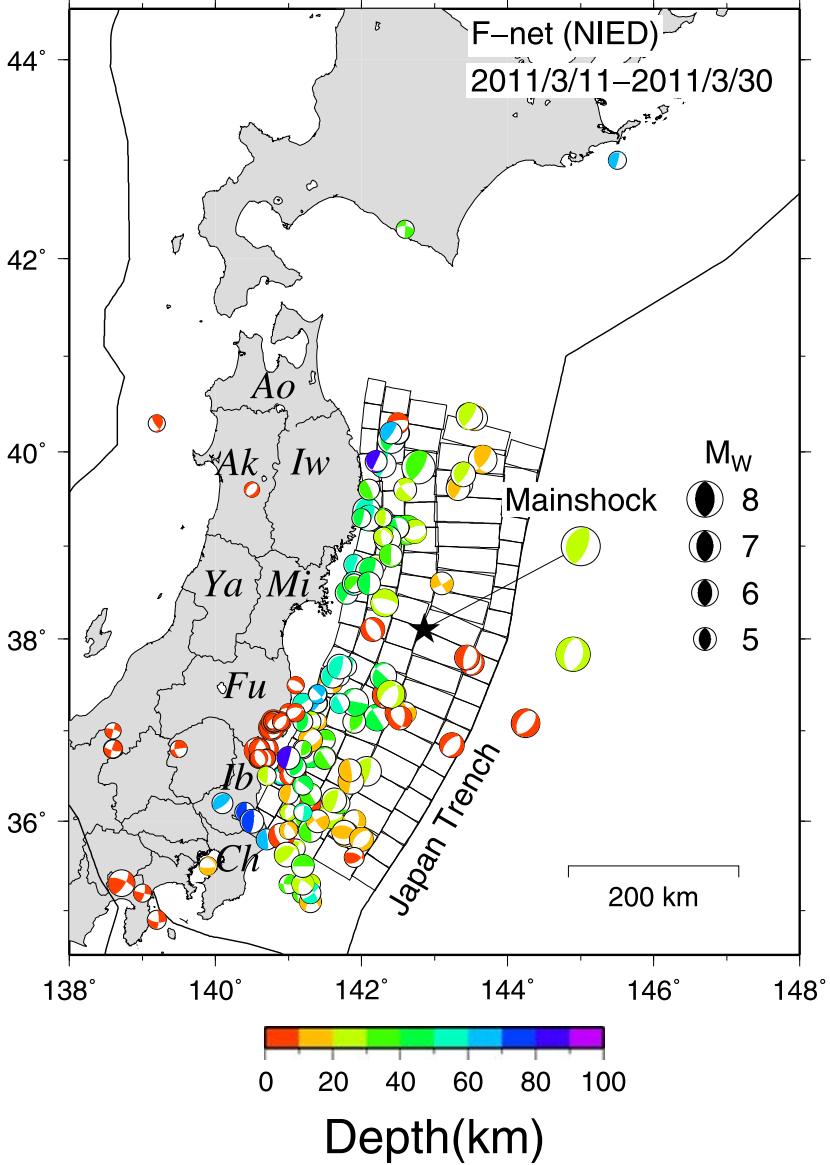

Fig. 2. Focal mechanisms of aftershocks determined by the F-net of NIED (http://www.fnet.bosai.go.jp/). The names of prefectures are abbreviated as follows: Ao Aomori; Ak Akita; Iw Iwate; Mi Miyagi; Ya Yamagata; Fu Fukushima; Ib Ibaraki; Ch Chiba. The rectangles indicate the fault model.

normal-fault aftershocks are observed, has a $\triangle \mathrm{CFF}$ of 0.5 1.0 MPa.

Because of the uncertainty of focal depth, it is not clear whether the offshore aftershocks with normal-fault mechanisms occurred above the plate interface of the subducted Pacific plate or not. Since there is a possibility that those events occurred within the subducted Pacific plate, we next investigate $\triangle \mathrm{CFF}$ for the target events located within the slab. The earthquake mechanisms within the slab are characterized by the down-dip compression (DDC) and downdip extension (DDE) types (e.g., Hasegawa et al., 1978; Yoshii, 1979). Here, we only target those events having a DDE mechanism which can be regarded as a kind of normal fault. Although the earthquakes with DDE mechanism generally occur at depths of about $30 \mathrm{~km}$ below the upper plate interface, we calculate the average of $\triangle \mathrm{CFF}$ obtained for three different depths, viz. 2, 15 , and $30 \mathrm{~km}$, below the upper plate interface. We also consider two cases for the fault dip. One is the fault dipping $45^{\circ}$ higher than the local dip of the plate interface. The other is the fault dipping $45^{\circ}$ lower than the local dip of the plate interface. In the deeper part of the slab where the dip of plate interface is greater than $30^{\circ}$, the former and latter give almost vertical and horizontal fault planes, respectively. In the shallower part, where the dip of the plate interface is very shallow, 

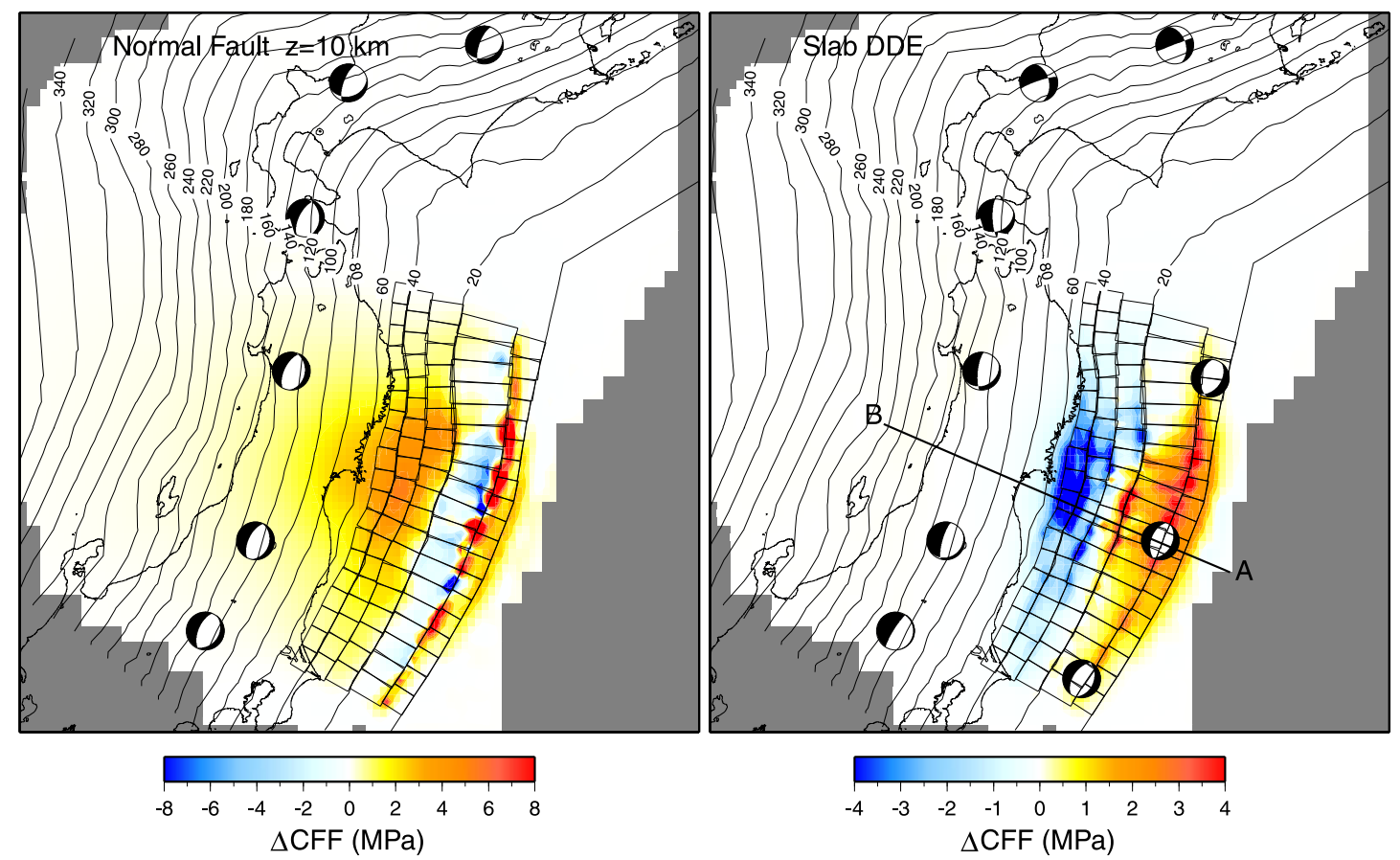

Fig. 3. Plan views of $\triangle \mathrm{CFF}$ for target events with a normal-fault mechanism in the shallow crust (left) and for target events with a DDE mechanism within the subducted Pacific plate (right). The average of $\triangle \mathrm{CFF}$ for the eastward and westward dipping faults is shown for the target events with a normal-fault mechanism (left), and the average for the six different faults is shown for the target events with a DDE mechanism (right) (see text for details). Mechanism diagrams shown at several selected points are those of eastward dipping faults (left) and westward dipping faults (right), respectively. Line A-B indicates the location of the profile in Fig. 4. The contour lines show the depth of the upper plate interface of the subducted Pacific plate every $20 \mathrm{~km}$. The rectangles indicate the distribution of fault segments.

the former gives a fault dipping westwards at approximately $45^{\circ}$, and the latter a fault dipping eastwards at the same angle. In Fig. 3(right), we show the average of $\triangle \mathrm{CFF}$ obtained for the six cases, i.e. three different depths below the plate interface for each fault dip. We find a pair of positive and negative lobes of $\triangle \mathrm{CFF}$ parallel to the trench. The centers of the lobes are situated near the fault segments of maximum slip. The boundary of the positive and negative lobes coincides with the $20 \mathrm{~km}$ depth contour of the plate interface. The aftershocks with normal-fault mechanisms near the trench (Fig. 2) are generally distributed over the positive lobe with amplitudes of 1-5 MPa. It is confirmed that this correlation is stronger when compared with the distribution of focal mechanisms derived from the Global CMT catalogue provided by USGS. The cross-sectional view of $\triangle \mathrm{CFF}$ along the profile A-B is shown in Fig. 4. It is shown that a positive $\triangle \mathrm{CFF}$ greater than $1 \mathrm{MPa}$ is spread downward up to $50 \mathrm{~km}$ from the upper plate interface. Furthermore, the cross-sectional view suggests that the normalfault aftershocks near the Japan Trench should occur within the subducted Pacific plate, whereas those on the west of the $20 \mathrm{~km}$ depth contour of the plate interface should occur in the crust above the plate interface. These details will be examined in the future.

Soon after the occurrence of the giant earthquake, there has been great concern that another large interplate event might be induced in the neighbouring regions. The $\triangle \mathrm{CFF}$ for the target events having a reverse-fault mechanism on the dipping plate interface is shown in Fig. 5(left). In order to reduce the near-field effect of stress singularities caused by artificial gaps and overlaps of the edges of adjacent fault

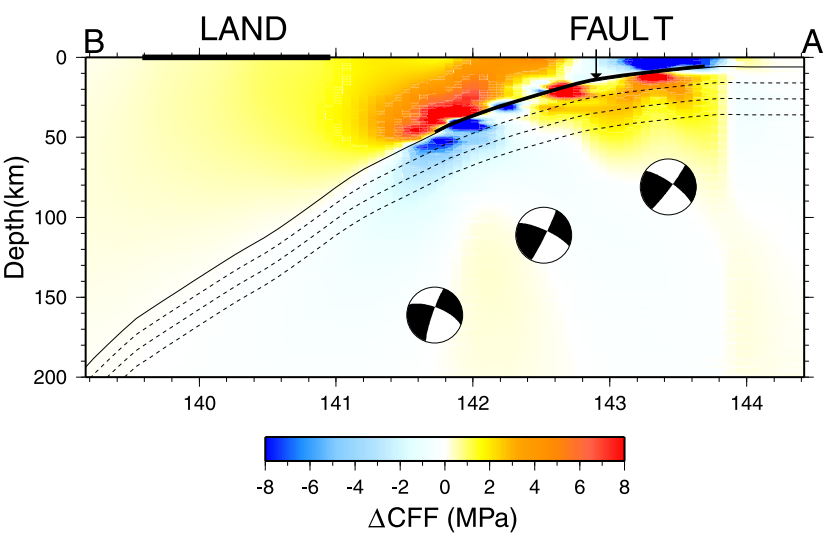

Fig. 4. Cross-sectional view of $\triangle \mathrm{CFF}$ for target events with a DDE mechanism along the profile A-B shown in Fig. 3(right). The average of $\triangle \mathrm{CFF}$ for the westward and eastward dipping faults is shown. Mechanism diagrams projected on the vertical cross-section are those of the westward dipping fault. The broken lines respectively indicate the positions 10,20 and $30 \mathrm{~km}$ below the plate interface.

segments, we evaluated $\triangle \mathrm{CFF}$ at places $2 \mathrm{~km}$ below the plate interface. Although it is natural that $\triangle \mathrm{CFF}$ is negative over the area where the coseismic slips are distributed, we find some scattered regions of positive $\triangle \mathrm{CFF}$ inside the main-shock fault zone. These are caused by the inhomogeneous slip distribution and the non-planar geometry of the plate interface. Theoretically, these positive regions should represent the sites where the interplate aftershocks with reverse-fault mechanisms are located (Fig. 2). Apparently, the correlation is not good. In order to discuss the cor- 

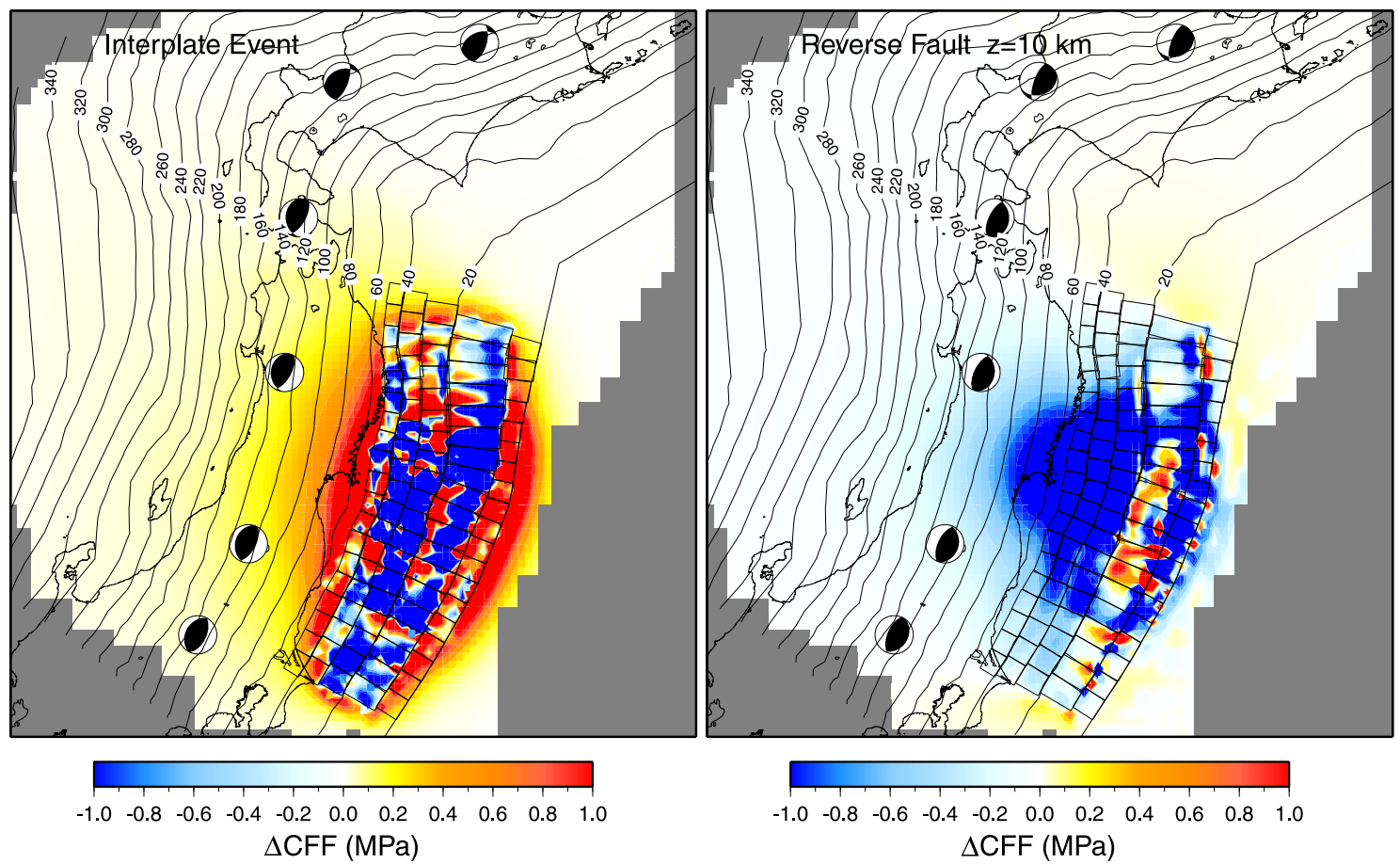

Fig. 5. Plan view of $\triangle \mathrm{CFF}$ for the target events with a reverse-fault mechanism on the megathrust plate boundary (left) and a reverse-fault mechanism in the shallow crust (right). The average of $\triangle \mathrm{CFF}$ for the eastward and westward dipping faults is shown for the target events with a reverse-fault mechanism in the shallow crust. Mechanism diagrams shown at several selected points are those of eastward dipping faults. The contour lines show the depth of the upper plate interface of the subducted Pacific plate every $20 \mathrm{~km}$. The rectangles indicate the distribution of fault segments.

relation with the locations of interplate aftershocks within the main-shock fault zone, it may be necessary that $\triangle \mathrm{CFF}$ is assessed using a slip distribution and fault geometry that contain more realistic short-wavelength irregularities, because $\triangle \mathrm{CFF}$ close to the plate interface depends greatly on such parameters.

For the interplate target events, the border areas of the main-shock fault zone are occupied by a large positive $\triangle \mathrm{CFF}$ in all directions (Fig. 5(left)). At the northern border, the fault adjoins the rupture zone of the 1994 SanrikuOki earthquake of $M_{\mathrm{w}}$ 7.7. Probably the $M_{\mathrm{w}} 9.0$ earthquake stopped there because the stress had already been released by the 1994 event. A positive $\triangle \mathrm{CFF}$ of approximately $0.1 \mathrm{MPa}$ is distributed over the area off the Pacific coast of the Aomori prefecture. The area corresponds to the northern half of the rupture zone of the 1968 Tokachi-oki earthquake $\left(M_{\mathrm{w}} 8.2\right)$ that was not fractured during the 1994 earthquake (Sato et al., 1996). At the southern border, a positive $\triangle \mathrm{CFF}$ of similar amplitude prevails over the area off the Pacific coast of the Chiba prefecture, where no large event has occurred since the 1677 Enpo earthquake $(\sim M 8)$. The observation of many interplate aftershocks in the depth range of 40-60 km (Fig. 2) is consistent with the strong positive $\triangle \mathrm{CFF}$ near the down-dip end of the fault zone. Beyond the depth of $60 \mathrm{~km}$, the still large positive $\triangle \mathrm{CFF}$ does not directly indicate a high probability for future interplate earthquakes because the slip over the area is considered to be aseismic. The area near the up-dip end of the fault zone, i.e. the area beyond the $10 \mathrm{~km}$ depth contour of the plate interface towards the trench, appears to be aseismic because no aftershocks with reverse-fault mechanisms have been observed near the trench so far (Fig. 2) despite the fact that the area is occupied by a strong positive $\triangle \mathrm{CFF}$.

Finally, we show the result for reverse faults in the shallow crust in Fig. 5(right). Focal depths are placed at $10 \mathrm{~km}$. The average of $\triangle \mathrm{CFF}$ obtained for the two fault dips, one dipping at $30^{\circ}$ eastwards and the other dipping at $30^{\circ}$ westwards, is shown. Expectedly, the spatial pattern of $\triangle \mathrm{CFF}$ is almost opposite to the result for normal faults shown in Fig. 3(left). A negative $\triangle \mathrm{CFF}$ of $0.1-1.0 \mathrm{MPa}$ is spread widely over the land area just west of the fault, with a decreasing amplitude towards the back arc side. The areas adjacent to the northern and southern borders of the fault are occupied by a positive $\triangle \mathrm{CFF}$ in the range $0.01-0.1 \mathrm{MPa}$. These results suggest that earthquakes having reverse-fault mechanisms in the shallow crust will be suppressed over the land area of Tohoku, although we recall that the Rikuu earthquake ( $M$ 7.2) took place near the border of Iwate and Akita prefectures two and half months after the occurrence of the 1896 Meiji Sanriku earthquake $(\sim M 8.5)$ that may have resulted in a similar stress change to the land area of Tohoku. Based on the fault model proposed by Tanioka and Satake (1996), we have assessed the $\triangle \mathrm{CFF}$ due to the 1896 Meiji Sanriku earthquake for the same reverse-fault targets and found that, although the $\triangle \mathrm{CFF}$ are similarly negative over the epicentral area of the Rikuu earthquake, their amplitudes are several ten times smaller than those due to the 2011 event. Probably, some other factor dominated the effect of negative $\triangle \mathrm{CFF}$, causing the Rikuu earthquake in 1896. This time it may be difficult for any unknown factors to trigger shallow reverse-fault earthquakes by superseding and negating the effect of a large negative $\Delta \mathrm{CFF}$ of $0.1-1.0 \mathrm{MPa}$. 


\section{Concluding Remarks}

The $\Delta$ CFF due to the 2011 off the Pacific coast of Tohoku Earthquake ( $\left.M_{\mathrm{w}} 9.0\right)$ has been investigated assuming several target faults in northeastern Japan. The increased activity of normal-fault earthquakes occurring after the main shock is explained by a large positive $\triangle \mathrm{CFF}$ of $1-5 \mathrm{MPa}$ prevailing over a vast area in and around the main-shock fault zone. As of May 9, 2011, the largest normal-fault aftershock near the Japan Trench was $M_{\mathrm{w}}$ 7.6. It occurred 40 minutes after the main shock. In the case of the great earthquake doublet along the central Kuril trench in 2006, an interplate earthquake of $M_{\mathrm{w}} 8.3$ was followed by a normalfault earthquake of $M_{\mathrm{w}} 8.1$ about 2 months later (Ammon et al., 2008). Because of the magnitude of positive $\Delta \mathrm{CFF}$, we cannot avoid suspecting that a great normal-fault earthquake of $M_{\mathrm{w}}>8$ may occur close to the trench in the near future. Also, we should be aware of the fact that the areas adjacent to the northern and southern borders of the fault, where other large interplate earthquakes might occur, are occupied by a positive $\Delta$ CFF of approximately $0.1 \mathrm{MPa}$. The $\Delta \mathrm{CFF}$ for the reverse faults in the shallow crust suggests that the future probability of reverse-fault earthquakes will be decreased in the land area of Tohoku.

Acknowledgments. We thank the Geospatial Information Authority of Japan (GSI) and the National Research Institute for Earth Science and Disaster Prevention (NIED) for promptly providing information on this earthquake. The authors are grateful to Dr. Okada for providing the source code for calculating the elastic deformation due to dislocation in a half space. The figures are prepared using GMT (Wessel and Smith, 1991). We thank two anonymous reviewers for critical reading of the manuscript and suggestions for its improvement. This study is partly supported by the urgent research for the 2011 off the Pacific coast of Tohoku Earthquake-inland seismic observation-, under the Research Program for Prediction of Earthquakes and Volcanic Eruptions, promoted by the Ministry of Education, Culture, Sports, Science and Technology (MEXT) of Japan.

\section{References}

Altamimi, Z., X. Collilieux, J. Legrand, B. Garayt, and C. Boucher, ITRF 2005: A new release of the international terrestrial reference frame based on time series of station positions and earth orientation parameters, J. Geophys. Res., 112, B09401, doi:10.1029/2007JB004949, 2007. Ammon, C. J., H. Kanamori, and T. Lay, A great earthquake doublet and seismic stress transfer cycle in the central Kuril islands, Nature, 451, 561-566, doi:10.1038/nature06521, 2008.

GSI, http://www.gsi.go.jp/cais/topic110314.2-index.html, March 14, 2011a.

GSI, http://www.gsi.go.jp/chibankansi/chikakukansi_tohoku.html, March 13, $2011 \mathrm{~b}$.

Hasegawa, A., N. Umino, and A.Takagi, Double-planed structure of the deep seismic zone in the northeastern Japan arc, Tectonophysics, 47, 43-58, 1978.

Okada, Y., Internal deformation due to shear and tensile faults in a halfspace, Bull. Seismol. Soc. Am., 82, 1018-1040, 1992.

Sato, T., K. Imanishi, and M. Kosuga, Three-stage rupture process of the 28 December 1994 Sanriku-Oki earthquake, Geophys. Res. Lett., 23, 33-36, 1996.

Takeuchi, M., T. Sato, and T. Shinbo, Stress due to the interseismic back slip and its relation with the focal mechanisms of earthquakes occurring in the Kuril and northeast Japan arcs, Earth Planets Space, 60, 549-557, 2008.

Tanioka, Y. and K. Satake, Fault parameters of the 1896 Sanriku tsunami earthquake estimated from tsunami numerical modeling, Geophys. Res. Lett., 23, 1549-1552, 1996.

Toda, T., R. S. Stein, P. A. Reasenberg, J. H. Dieterich, and A. Yoshida, Sress transferred by the $1995 \mathrm{Mw}=6.9$ Kobe, Japan, shock: Effect on aftershocks and future earthquake probabilities, J. Geophys. Res., 103, 24,543-24,565, 1998.

Wessel, P. and W. H. F. Smith, Free software helps map and display data, Eos Trans. $A G U, \mathbf{7 2}, 441,1991$.

Yoshii, T., A detailed cross-section of the deep seismic zone beneath northeastern Honshu, Japan, Tectonophysics, 55, 349-360, 1979.

S. Hiratsuka and T. Sato (e-mail: tamao@cc.hirosaki-u.ac.jp) 